Conference Proceedings Paper

\title{
Surface Topography and Grain Morphology of Nanolayer TiAlN/TiSIN Coating Governed by Substrate Material and Rotation during Deposition
}

\author{
Vladimir Terek ${ }^{1, *}$, Aleksandar Miletić ${ }^{1}$, Lazar Kovačević ${ }^{1}$, Dragan Kukuruzović ${ }^{1}$, \\ Branko Škorić ${ }^{1}$, Peter Panjan ${ }^{2}$ and Pal Terek ${ }^{1}$ \\ 1 Faculty of technical sciences, University of Novi Sad, Trg Dositeja Obradovića 6, 21000, Novi Sad, Serbia; \\ miletic@uns.ac.rs (A.M.); lazarkov@uns.ac.rs (L.K); kukuruzovic@uns.ac.rs (D.K.); skoricb@uns.ac.rs (B.Š); \\ palterek@uns.ac.rs (P.T.) \\ 2 Jožef Stefan Institute, Jamova 39, 1000, Ljubljana, Slovenia; peter.panjan@ijs.si (P.P.) \\ * Correspondence: vladimirterek@uns.ac.rs; Tel.: +381-21-485-2330
}

Received: 4 April 2020; Accepted: 11 May 2020; Published: 12 May 2020

\begin{abstract}
Nanolayer TiAlN/TiSiN coating is one of the most advanced contemporary protective coatings. It has been applied for protection of machining tools, forming tools, and die casting tools. However, due to its versatile properties, there is a high potential for broadening its application, for example for protection of biomedical implants. Each application requires specific base materials, for example cold working steels are used for forming, while stainless steels are applied for biomedical purposes. Different materials and their pre-treatment might result in different coating properties even if coating was conducted in a single batch. Real tools and components have complex geometries, and as such require a multiple-axis rotation during the deposition. Among other properties, grain morphology and surface topography are of great importance in a real application. Since systematic studies on the effect of substrate materials and rotation during deposition on these properties are very scarce, in this article we studied TiAlN/TiSiN coating magnetron sputtered on five different substrates, prepared with 1 fold, 2-fold, and 3-fold rotations. Cold-work tool steel (X153CrMoV12), hot-work tool steel (X37CrMoV5-1), plasma nitrided hot-work tool steel, surgical stainless steel (X2CrNiMo18-15-3), and cemented carbide (WC/Co) were used as substrate materials. 3D stylus profilometry and atomic force microscopy were used for evaluation of micro and nano topography. The coated surgical steel has the highest roughness (Sa) which corresponds to the highest number of coating growth defects. However, the size of the individual growth defects was considerably smaller for this substrate than for other substrate materials. The observed difference is linked to differences in the concentration of specific carbides contained in a specific steel. Since different carbides have different polishing and ion-etching rates, coatings on different steels may have different concertation of defects. Columnar grain analysis revealed that coating on surgical steel exhibited the smallest column diameter $(125 \mathrm{~nm})$ and their highest uniformity. Column diameter on other substrates is around $215 \mathrm{~nm}$, while hot-working tool steel exhibited the largest columns $(235 \mathrm{~nm})$. Such finding suggests that the same coating may exhibit different mechanical properties on different substrates. Coatings produced with the higher degree of rotation (2-fold, 3fold) have less defects and smoother surface. There was no clear trend between columnar grain size and number of rotational degrees.
\end{abstract}

Keywords: magnetron sputtering; nanolayer coating; TiAlN/TiSiN; grain morphology; topography 


\section{Introduction}

Owing to its high mechanical properties, oxidation resistance, thermal stability and tribological performance, nanolayer TiAlN/TiSiN coating presents one of the most advanced contemporary protective coatings. Although it is developed for application on heavily stressed cutting tools such as tools for dry and high-speed machining it has a potential for application on other kinds of material processing tools. It is suitable for application on forming tools, forging tools, high pressure die casting tools, and on different machine components. Due to its high mechanical properties, high corrosion resistance, and chemical inertness this coating is promising for application on biomedical implants and devices. Broadening the application of coatings to another fields usually comes with their deposition on different, less conventional, substrate materials. Application of coatings on different materials might result in different coating properties even though the deposition is performed in the same production batch.

Tailoring the coatings properties to specific purposes requires understanding of their microstructure, topography and mechanical properties but also the interrelationship between these properties. The coatings topography is important for their tribological and corrosion behavior [1,2], while coatings microstructure (grain morphology) governs their mechanical properties, fracture behavior, and their tribological performance [3]. Besides the initial substrate roughness, the coatings topography greatly depends on the kind of applied deposition process, employed parameters, and the type of substrate material.

Magnetron sputtering (MS) is a widely applied industrial deposition process known for production of high quality, dense coatings with relatively low roughness and residual stresses. However, considering that this process is line-of-site deposition, micro and nano surface morphological features present on the substrate affect the coating growth and cause formation of defects in the coating layer [2]. Growth defects are discontinuities in coating material in form of peaks (nodular defects) and valleys (cavities) [4]. Nodular defects mostly form due to the presence of various asperities on substrate surfaces and particles of different origin [4]. Besides deposition system, which generates a lot of particles that cause defects, the substrate material and its microstructure also greatly influence the formation of defects and their concentration. Nodular defects caused by microstructure form due the differences in polishing and/or ion etching rates between the various phases of materials [4]. For example, metal carbides contained in tool steels have lower polishing and sputtering rate than the surrounding matrix. Cavity defects form due to the presence of micro/nano cavities on the substrate and due to the popping-out of nodular defects during the deposition process. Growth defects define the coatings topography, which consequently affect its tribological properties, adhesion, and corrosive behavior [1,2,4]. Influence of defects on coatings performance can be so pronounced that the influence of chemical composition, microstructure and architecture might be exceeded. Therefore, investigations that concern formation of defects in coatings produced by MS are very important for development of new coatings and widening their industrial application.

Transitional metal-nitride coatings produced by MS typically exhibit columnar grain microstructure. Considering that coating mechanical properties and fracture greatly depend on its grain shape and size, in recent years, this topic caught a significant scientific attention $[5,6]$. Investigations from the field addressed the effects of coatings chemical composition $[7,8]$, ion bombardment of a growing film, deposition temperature [9,10], substrate bias [3], sputtering target current [11], type of deposition technology [6], and the effects of different coating layers [5,12] on the coating grains morphology. Thornton's structure zone diagram (SZD) was developed to estimate the effects of few deposition parameters on coating microstructure obtained by sputtering. Although it has some serious limitations concerning the real deposition systems, it has been used for years. Recently few groups of authors modified the model and incorporated additional deposition parameters in consideration. Finally, proposed by Anders [13], it evolved to SZD that accounts energetic deposition processes. However, all these models cannot predict the effects of specific combinations of substrate/coating materials and deposition conditions [13], such as coatings rotation 
during deposition. Additionally, literature is scarce on papers addressing the effects of substrate materials (tool steels) and rotation during deposition on coatings topography and grain morphology.

Focused ion beam (FIB) and transmission electron microscopy (TEM) are the most sophisticated techniques applied for studying the coating grain morphology. However, atomic force microscopy (AFM) is an easier to use, cheaper, and more accessible method for studying the coatings columnar grain morphology. In addition, no special sample preparation is required for AFM measurements. When coupled with image software analysis this technique provides a significant amount of valuable quantitative data.

In this work, the effects of different metallic substrate materials and rotation during deposition on the topography and coating grain size are evaluated for nanolayer TiAlN/TiSiN coating deposited by industrial unbalanced magnetron sputtering unit.

\section{Materials and Methods}

\subsection{Sample Preparation and Coating Deposition}

Nanolayer TiAlN/TiSiN coating was deposited on: quenched and tempered cold-work tool steel (EN X153CrMoV12), hot-work tool steel (EN X37CrMoV5-1), plasma nitrided hot-work tool steel (EN X37CrMoV5-1), hot rolled surgical stainless steel (EN X2CrNiMo18-15-3), and cemented carbide (WC/Co). Disk shaped samples, with dimensions of Ø32 $55 \mathrm{~mm}$ were prepared. The steel samples were ground and polished by a $3 \mu \mathrm{m}$ diamond polishing paste. Prior to coating, deposition samples were degreased and cleaned in ultrasonic baths with deionized water and detergents and dried in hot air.

The coating was produced by DC magnetron sputtering in an industrial unit CC800/9 (CemeCon). The unit is equipped with four unbalanced planar magnetron sources arranged in the corners of a chamber (Figure 1). Details about deposition process are given in [14]. The coating was deposited on all five different substrate materials with 2-fold rotation, while cold-work tool steel was additionally coated employing 1-fold and 3-fold rotations. Designation of samples used in this study is given in Table 1. All samples were prepared in a single deposition batch.

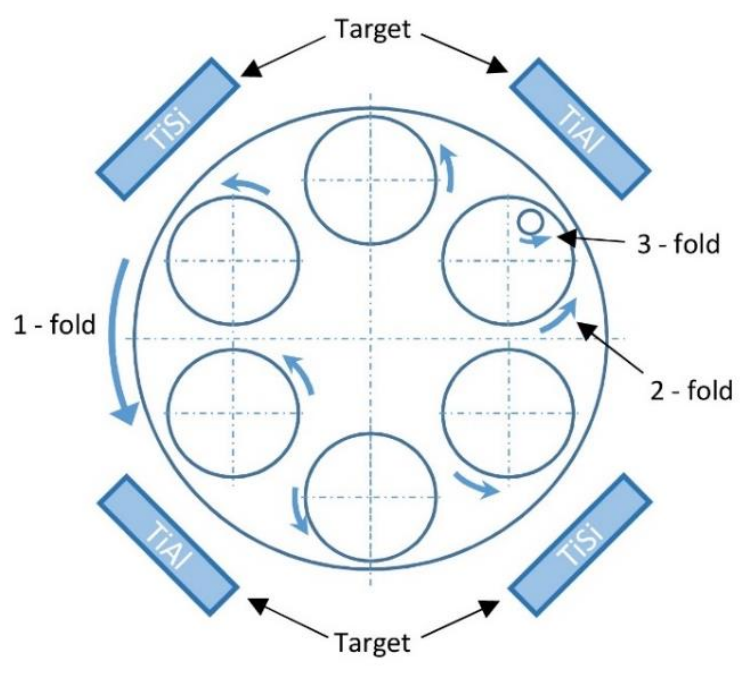

Figure 1. Schematic of substrate holder and position of targets. 
Table 1. Samples designation.

\begin{tabular}{cccccc}
\hline $\begin{array}{c}\text { Rotation During } \\
\text { Deposition }\end{array}$ & $\begin{array}{c}\text { Cold-Work } \\
\text { Tool Steel }\end{array}$ & $\begin{array}{c}\text { Hot-Work } \\
\text { Tool Steel }\end{array}$ & $\begin{array}{c}\text { Plasma Nitrided } \\
\text { Hot-Work Tool } \\
\text { Steel }\end{array}$ & $\begin{array}{c}\text { Surgical } \\
\text { Stainless Steel }\end{array}$ & $\begin{array}{c}\text { Cemented } \\
\text { Carbide }\end{array}$ \\
\hline 1-fold & CW-1f & - & - & - & - \\
2-fold & CW-2f & HW & PN & SS & CC \\
3-fold & CW-3f & - & - & - & - \\
\hline
\end{tabular}

\subsection{Coatings Characterization}

In order to determine mechanical properties of the coating, Fisherscope H100C tester equipped with Vickers diamond indenter was used. The maximal indentation depth was kept below $10 \%$ of the coating thickness. To achieve this, loads of $50 \mathrm{mN}$ were applied. Hardness $(\mathrm{H})$ and modulus of elasticity (E) were calculated using Oliver-Pharr method [15]. For calculation of the indentation modulus (E) Poisson's ratio of 0.25 was used. Measured hardness and elastic modulus of coating on HW substrate was $2334 \mathrm{HV}_{0.005}$ and $289.62 \mathrm{GPa}$, respectively.

Coating thickness was measured using ball cratering method. Thickness of the coating deposited using 1-fold, 2-fold and 3-fold rotation was $6.38 \mu \mathrm{m}, 3.6 \mu \mathrm{m}$ and $2.6 \mu \mathrm{m}$, respectively

Surface topography was evaluated using 3D stylus profilometry (Taylor Hobson Talysurf). The scanning area was $1 \mathrm{~mm} \times 1 \mathrm{~mm}$, with resolution of few tens of $\mathrm{nm}$ in $z$ direction, $1 \mu \mathrm{m}$ in $x$ direction and $2 \mu \mathrm{m}$ in $y$ direction. In order to study the coatings topography on a nano level, atomic force microscopy (AFM) was employed. For this purpose CP-II di (Veeco) instrument was used. For roughness evaluations area of $90 \mu \mathrm{m} \times 90 \mu \mathrm{m}$ was scanned, while for high resolution evaluations and detailed examinations of columnar grains area of $5 \mu \mathrm{m} \times 5 \mu \mathrm{m}$ was scanned. All AFM images were acquired in contact mode using a symmetrically etched silicon-nitride probe. Scan rate, and set point were kept at $1 \mathrm{~Hz}$, and $225 \mathrm{nN}$ respectively.

Scanning Probe Image Processor (SPIP, Image Metrology A/S) image analysis software was employed for determination of surface roughness and size of columnar grain. The number of coating growth defects (islands) was evaluated by using different thresholds which were determined in work of Panjan et al. [16]. A value of $0.5 \mu \mathrm{m}$ was chosen as the threshold for detecting both islands and cavities.

\section{Results}

\subsection{Topography and Grain size of Coatings Deposited on Different Substrate Materials}

Two representative 2D and 3D topography images of cemented carbide (CC) and stainless steel (SS) samples are presented in Figure 2. Spike-like features found on these images are nodular growth defects (defects), typical for coatings produced by industrial magnetron sputtering unit. SS sample displayed more defects compared to CC. However, the defects for CC sample appear larger. 


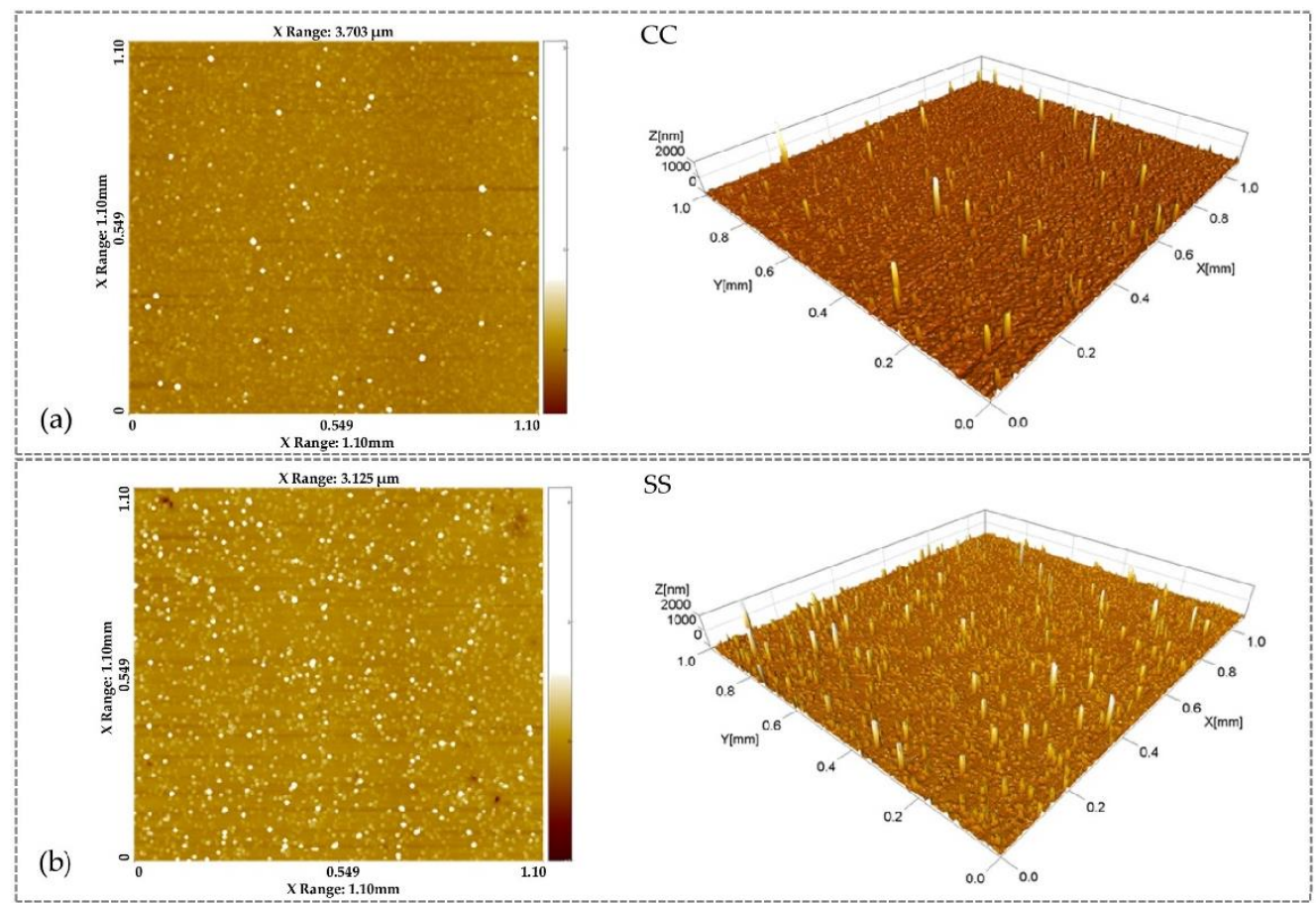

Figure 2. 2D and 3D topography images obtained by profilometry on areas of $1 \mathrm{~mm}^{2}$ : (a) CC sample; (b) SS sample.

By analysis of 2D profilometry images, it was found that nodular defects on SS sample are arranged in a shape of a net. Formation of such features was not typical for other samples.

Arithmetical mean roughness parameter (Sa) and density of nodular growth defects is for different samples shown in Figure 3. SS sample exhibited the highest roughness $(\mathrm{Sa}=76.7 \mathrm{~nm})$. Other samples exhibited approximately similar roughness Sa (ranging from $44.7 \mathrm{~nm}$ to $53.5 \mathrm{~nm}$ ) which is considerably lower than for SS sample. The highest density of coating growth defects was detected on SS sample $\left(338 / \mathrm{mm}^{2}\right)$. Density of defects on other samples was considerably lower, ranging from $96 / \mathrm{mm}^{2}$ to $166 / \mathrm{mm}^{2}$. This is in agreement with topography images presented in Figure 2 . On the other side, it was found that the overall volume of defects $(V)$ is smaller for SS (Vss $=14.82 \mu \mathrm{m}^{3}$ ) than for other samples $\left(V_{c C}=28.64 \mu m^{3} ; V_{H W}=29.27 \mu m^{3} ; V_{C W-2 f}=38.75 \mu m^{3} ; V_{P N}=44.37 \mu m^{3}\right)$.

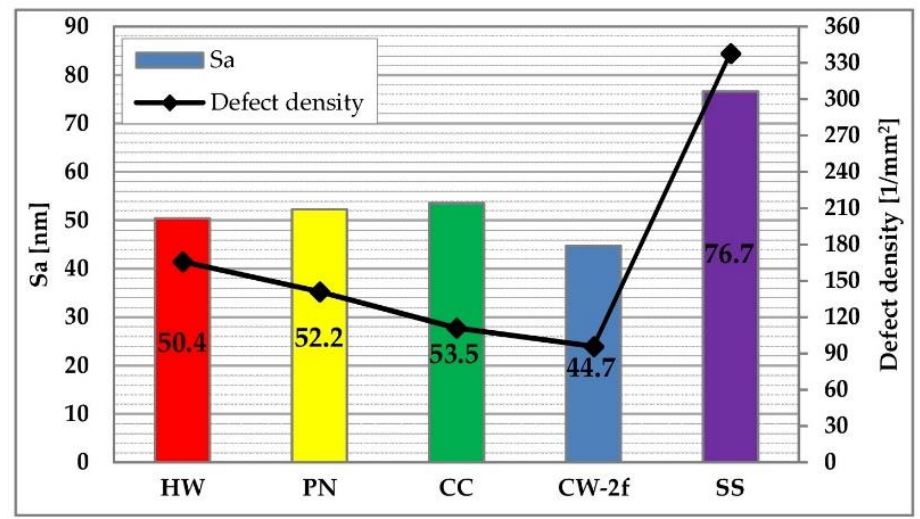

Figure 3. Arithmetical mean roughness parameter (Sa) and density of nodular defects of different samples, determined on area of $1 \mathrm{~mm}^{2}$.

Figure 4 presents higher resolution surface topography images of two representative samples, CC and SS, acquired by AFM on the areas of $90 \mu \mathrm{m} \times 90 \mu \mathrm{m}$. Besides growth defects, which were 
observed by tactile 3D profilometry, higher-resolution AFM images bring additional information on the topographical features. I might be seen that the height of those features, in between the defects, is smaller for SS sample. Values of surface roughness, determined on areas of $90 \mu \mathrm{m} \times 90 \mu \mathrm{m}$, were different than those obtained by 3D tactile profilometry on areas of $1 \mathrm{~mm}^{2}$. Lower roughness was determined for HW, PN, and SS sample, 15, 15, and $14 \mathrm{~nm}$, respectively. CC, and CW-2f sample displayed higher roughness of 27.2 and $28.1 \mathrm{~nm}$, respectively. This is not in agreement with results (trends) obtained by profilometry, because the random selection of small scanning areas resulted in fluctuation of defect density on the examined surfaces.
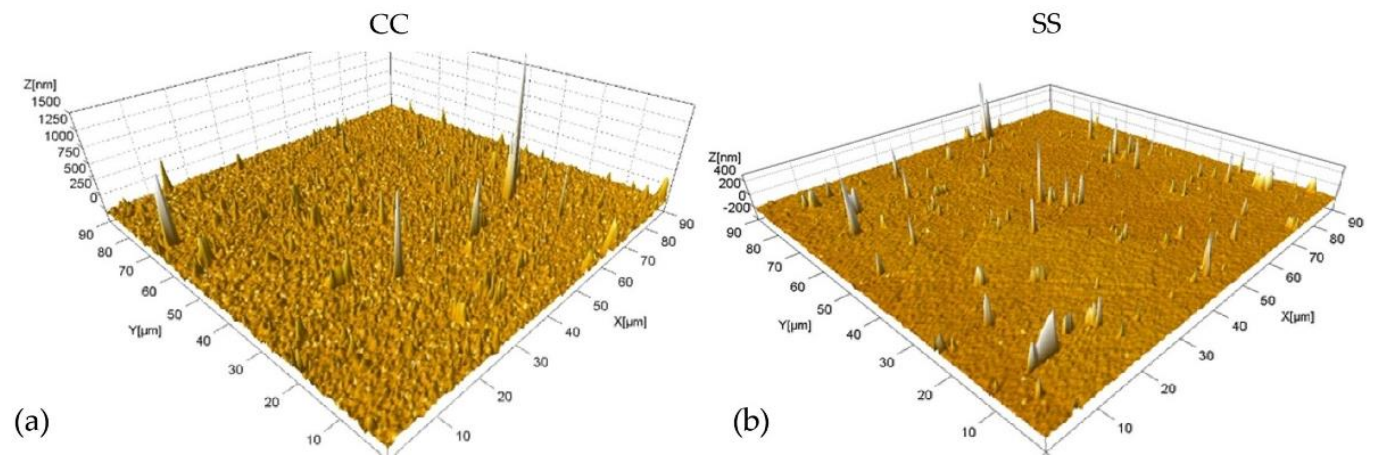

Figure 4. Surface topography obtained by AFM on areas of $90 \mu \mathrm{m} \times 90 \mu \mathrm{m}$ : (a) CC sample; (b) SS sample

To study the coatings nano-topography between the nodular defects, areas of $5 \mu \mathrm{m} \times 5 \mu \mathrm{m}$ were scanned by AFM. Figure $5 \mathrm{a}$ and b shows $5 \mu \mathrm{m} \times 5 \mu \mathrm{m}$ 3D AFM images of two representative samples, CC and SS. The semi-circular shapes of the asperities, present on surfaces of both samples, are the tops of the coatings' columnar grains. Compared to the other samples, it appears that SS sample has smaller, more uniform grains, and considerably smoother surface. Surface roughness parameters of scanned $5 \mu \mathrm{m} \times 5 \mu \mathrm{m}$ areas are presented in Figure $5 \mathrm{c}$. It is clear that the SS sample exhibited the lowest roughness $(7.9 \mathrm{~nm})$.
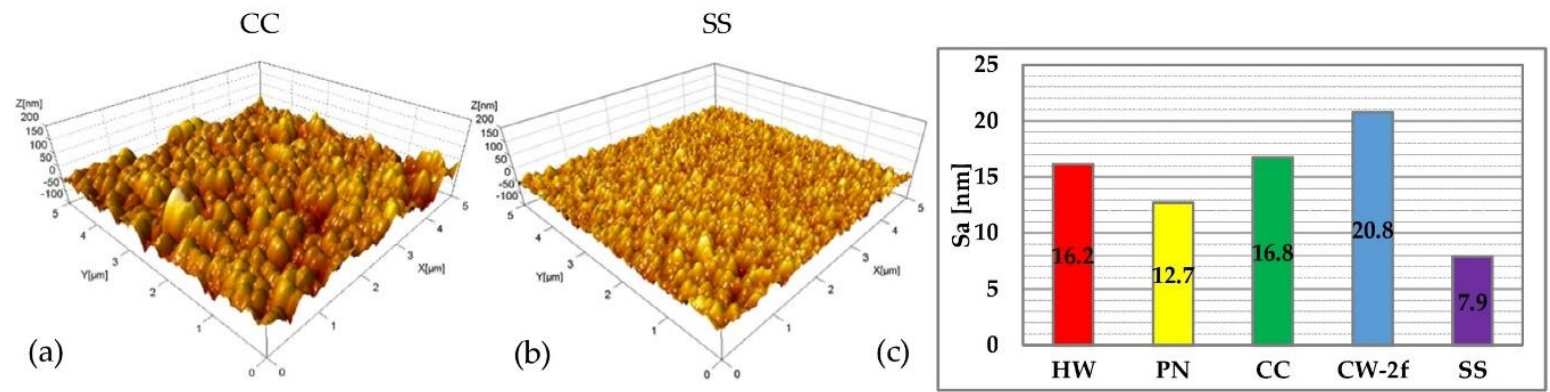

Figure 5. AFM surface analysis on areas of $5 \mu \mathrm{m} \times 5 \mu \mathrm{m}$ : (a) Surface topography of CC sample; (b) Surface topography of SS sample; (c) Arithmetical mean height roughness parameter (Sa) of different samples.

In order to investigate differences in grain size, grain analysis was performed for all investigated samples. For these purposes, 2D AFM images of $5 \mu \mathrm{m} \times 5 \mu \mathrm{m}$ were used. Example of grain analysis is shown in Figure 6a for CC sample. The quantitative results obtained for different samples are presented in Figure $6 \mathrm{~b}$. The largest number of grains was determined for SS sample (1580), which means that this sample has the smallest grains. Lower and similar number of grains (ranging between 490 and 614) was found for other samples. Mean grain diameter for SS sample is $125.6 \mathrm{~nm}$, while for other samples ranges from $211.4 \mathrm{~nm}$ to $236.8 \mathrm{~nm}$. 

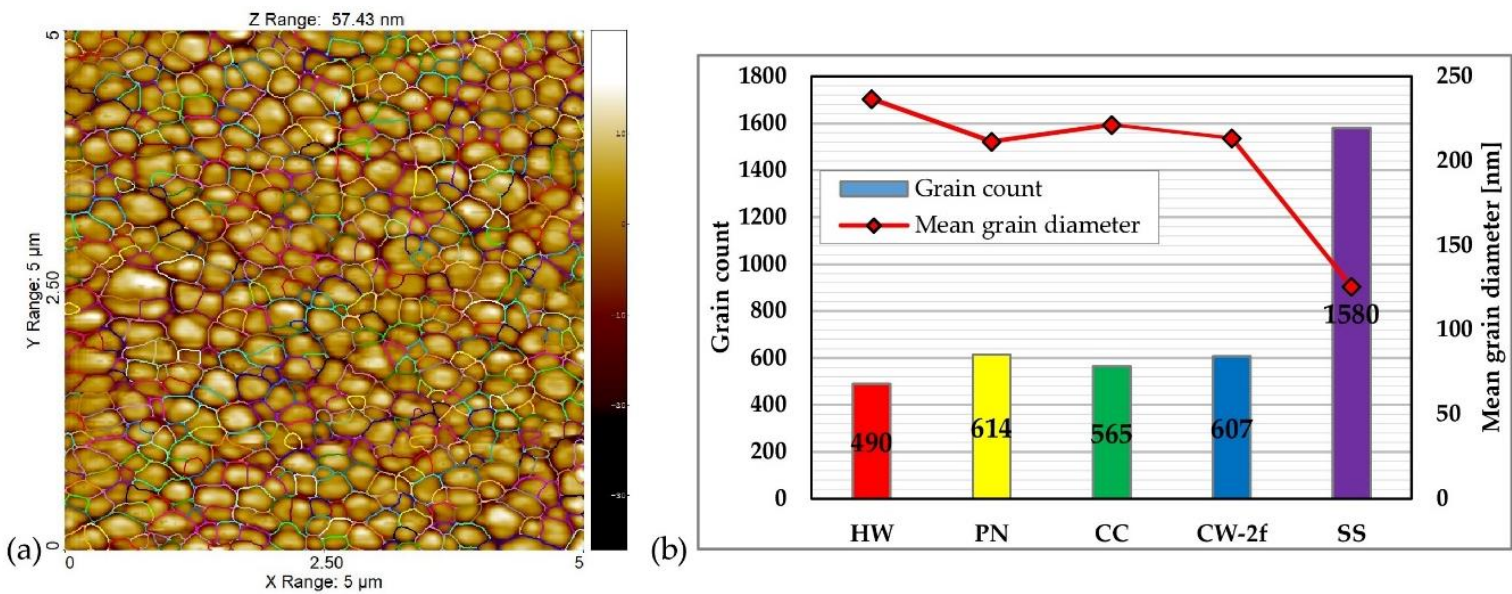

Figure 6. Grain analysis on areas of $5 \mu \mathrm{m} \times 5 \mu \mathrm{m}$ : (a) Example of grain analysis of CC sample; (b) Grain count and mean grain diameter of different samples.

\subsection{Topography and Grain Size of Coatings Deposited on CW Sample with Different Rotations}

Surface roughness and density of nodular defects, determined by profilometry, is for CW samples deposited with different rotations presented in Figure 7. CW-2f and CW-3f samples exhibited almost the same surface roughness which is considerably lower than that obtained for CWIf sample. Generally, surface roughness (Sa) decreased with increased degree of rotation during deposition. With increased degree of rotation, also a declining trend of defect density is observed.

Figure 8 presents 3D topography images of $5 \mu \mathrm{m} \times 5 \mu \mathrm{m}$ areas of CW-1f, CW-2f, and CW-3f samples. The images were obtained by AFM measuring the zones between defects. Analysis of images presented in Figure 8. leads to several findings. First, the surface roughness decreased with increase in number of rotations. Second, the grain size appears to be the smallest for CW-1f sample and the highest for CW-2f sample. Third, on CW-1f sample the grains are agglomerated in groups and surface of this sample is quite uneven. Grain agglomeration is less pronounced for CW-2f and even less for CW-3f samples. Fourth, when compared to other two samples, CW-3f sample has the most uniform surface, which is in agreement with Sa parameter determined for measurements on 5 $\mu \mathrm{m} \times 5 \mu \mathrm{m}$ area. $\mathrm{CW}-3 \mathrm{f}$ exhibited lower value of Sa $(\mathrm{Sacw}-3 \mathrm{f}=15.3 \mathrm{~nm})$ than other samples deposited at lower degree of rotation $(\mathrm{Sacw}-1 \mathrm{f}=41.0 \mathrm{~nm}$; Sacw-2f $=20.8 \mathrm{~nm})$.

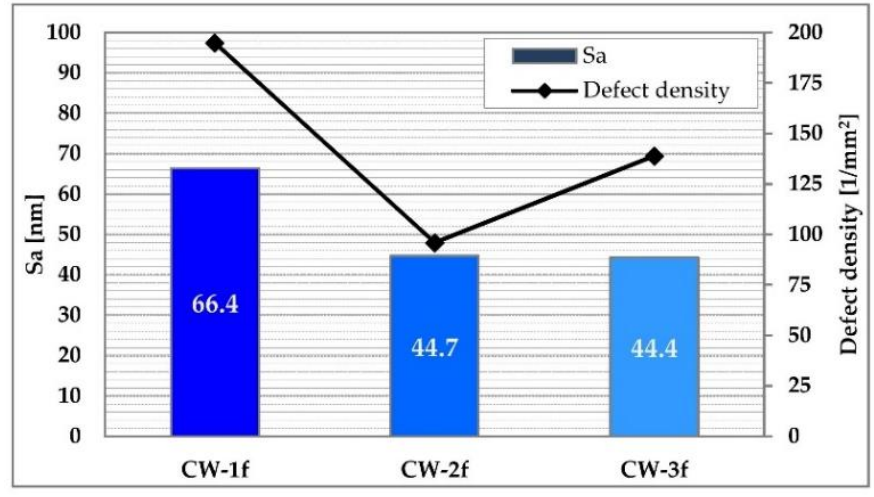

Figure 7. Arithmetical mean roughness parameter (Sa) and density of nodular defects of CW samples deposited with different degrees of rotation, determined on area of $1 \mathrm{~mm}^{2}$. 

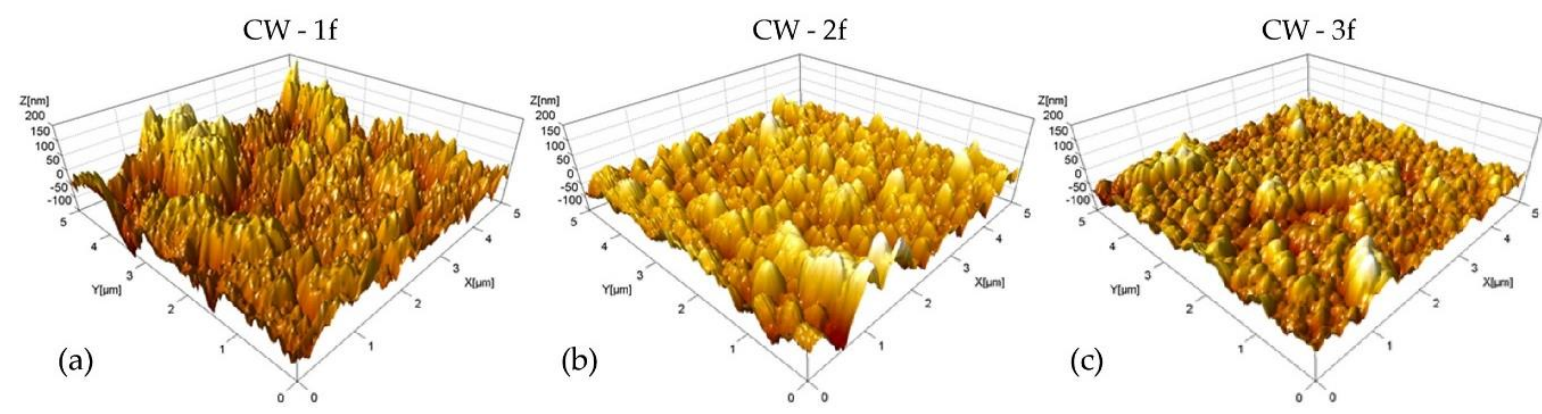

Figure 8. Surface topography obtained by AFM on areas of $5 \mu \mathrm{m} \times 5 \mu \mathrm{m}$ : (a) CW-1f sample; (b) CW2f sample; (c) CW-3f sample.

Results of grain analysis performed on CW samples deposited with different rotations are presented in Figure 9. Analysis was performed on 2D AFM images of $5 \mu \mathrm{m} \times 5 \mu \mathrm{m}$ areas. CW- $1 \mathrm{f}$ sample contained the largest number of grains (1376), while CW-2f and CW-3f contained less grains, 607 and 1060, respectively. Accordingly, the largest mean grain diameter was determined for CW-2f sample (213.5 nm), next was CW-3f sample (162 nm), and CW-1f sample exhibited the smallest mean grain diameter $(136.2 \mathrm{~nm})$. Generally, a specific trend in grain size dependency on degree of rotation was not observed.

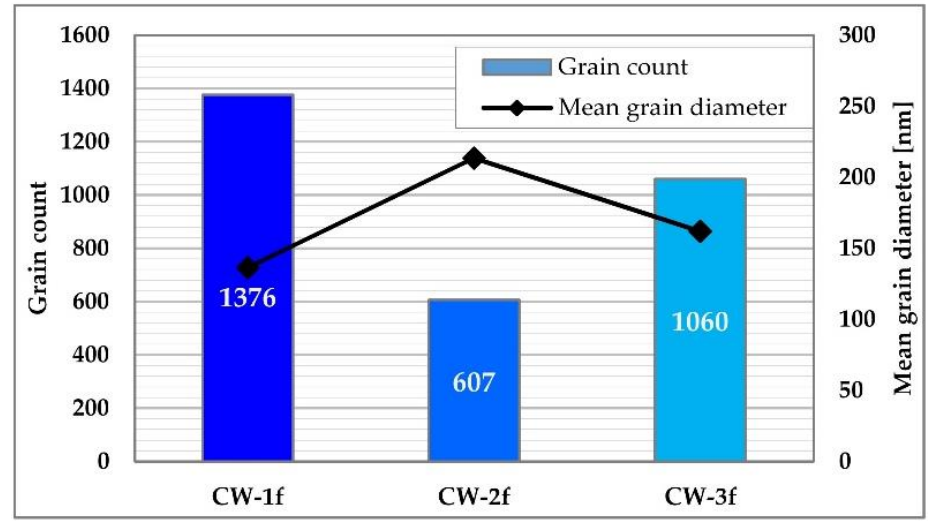

Figure 9. Grain count and mean grain diameter of CW samples deposited with different rotations.

\section{Discussion}

\subsection{Effect of Substrate Materials On Topography and Coating Grain Size of TiAlSiN Nanolayer Coating}

Substrate materials used in this study can be divided in two groups. Tool materials (CW, HW, $\mathrm{PN}$, and $\mathrm{CC}$ ) belong in the first group, while stainless steel belongs in the second group. The main differences between these groups of materials are their microstructure and mechanical properties. Different coating surface topography and surface roughness were found for these two groups. Coatings deposited on tool materials displayed lower roughness and less defects, while coatings on stainless steel are of high roughness and contain more defects, Figure 3. Good correlation between the surface roughness and density of defects was observed.

Comparable chemical composition, microstructure and precipitation of quite similar carbides in all investigated tool material samples resulted in their approximately same behavior. In these cases, the same density of growth defects was obtained. On the other hand, stainless steel sample does not contain carbides in its microstructure but exhibited the highest number of defects $[17,18]$. This indicates that formation of nodular defects on stainless steel sample has different origin. Stainless steel substrate has the lowest hardness $(<200 \mathrm{HV})$ among investigated materials. It is postulated that, because of low hardness, a large number of deformed micro/nano asperities on the surface may form 
during the surface preparation by grinding and polishing. Additionally, sandpaper or diamond paste particles more easily embed into such a soft substrate. Both mentioned effects are usually more pronounced at steel grain boundaries. Overall, these effects caused formation of larger number of nodular defects on SS sample, which are distributed in pattern that follows the shape of the underlying substrate grain boundaries.

Generally, the topography of all investigated samples appears quite similar because it is dominated by nodular defects. However, their nano-topography between the nodular defects appears considerably different. Again, surgical stainless steel displayed different behavior than other investigated substrate materials. In the areas between nodular defects SS sample exhibited the lowest surface roughness (Figure 5), which is attributed to smaller and more uniform coating grains determined for this sample, Figure $6 \mathrm{~b}[6]$.

Coatings deposited on the group of tool materials exhibited larger grains than the coating deposited on surgical stainless steel. The fact that all samples were deposited under the same conditions in the same batch, indicates that the observed differences in the grain size may only arise as a consequence of the different coating growth on materials with different microstructures. Substrates belonging to the group of tool materials mostly contain tempered martenzite in their microstructure. On the other side, the microstructure of a stainless steel comprises of austenite [18]. Therefore, it is suggested that coatings grown on substrates with martenzite (except CC sample) displayed larger grains and uneven surface morphology, while coatings grown on substrates with austenite microstructure exhibited smaller grains and smooth surfaces. Diameter of columnar grains obtained on surgical steel $(125 \mathrm{~nm})$ belongs to group of fine columnar grains. Considering that smaller grains lead to better mechanical properties and increased resistance to crack propagation, coating deposited on stainless steel substrate is expected to demonstrate higher mechanical properties.

\subsection{Effect of Rotation on Topography and Coating Grain Size}

Coatings deposited with different degrees of rotation displayed differences in their surface roughness (Sa). Decrease of roughness was detected on coating deposited with higher degree of rotation, Figure 7. As indicated in Chapter 2.2, the coating thickness decrease with increase in degrees of rotation. Considering that the coating thickness affects its roughness $[4,8]$, it is suggested that the observed trend is related to the effects of coating thickness, and not solely to effects of rotation during deposition. Additionally, it is postulated that nodular defects of thicker coatings (1-fold, 2-fold) may grow higher and more easily above the set detection threshold of $0.5 \mu \mathrm{m}$. Consequently, this would raise the surface roughness (Sa). Therefore, it is proposed that future investigations of substrate rotation on coatings roughness should be performed on coatings with the same thickness.

Coating deposited with 1-fold rotation exhibited smaller grains than the coating deposited with 2-fold and 3-fold rotation, Figure 9. Although it is expected that coating with smaller grains should exhibit lower surface roughness, quite the opposite behavior was discovered. Coating deposited with 1 -fold rotation displayed higher surface roughness than 2 -fold and 3-fold coatings, Figure 7. The observed increase in surface roughness, of the coating deposited with 1-fold rotation, is addressed to pronounced grain agglomerations and formation of surface with uneven morphology. On the other side, coatings produced with higher degree of rotations exhibited lower roughness due to more even surfaces. Similar behavior was observed by Gselman for TiAlN/CrN nanolayer coating [19]. Higher degree of rotation (2-fold, 3-fold) decreases the deposition rate [20] and increases ion bombardment of the growing film. It is known that higher ion bombardment increases the adatom mobility which consequently results with films of lower surface roughness [8]. The grain agglomeration and uneven surface topography detected for coating deposited using 1-fold rotation is a result of high deposition rate and low ion bombardment. Generally, no specific trend of columnar grain size on degrees of rotation was observed.

In order to better understand the influence of substrate rotation during deposition on grain size, additional research is required. Such research should include a larger number of samples and/or experiment repetitions and surface evaluations on more points on coated samples (3 to 6). 
Additionally, besides AFM analysis surfaces should be also analyzed by other microscopy techniques.

\section{Conclusions}

In presented study, nanolayer TiAlN/TiSiN coating was deposited on five different substrate materials using 1-fold, 2-fold and 3-fold rotation. Influence of substrate material and degree of rotation on coating topography and grain size was investigated. From presented investigation the following conclusions can be drawn:

- For investigated cases it was found that the coating surface roughness (Sa) is directly correlated with number of nodular growth defects.

- Coating deposited on surgical stainless-steel substrate (EN X2CrNiMo18-15-3) exhibited higher roughness and defect density than the coating deposited on investigated tool materials (EN X153CrMoV12, EN X37CrMoV5-1, plasma nitrided EN X37CrMoV5-1, and WC/Co). The investigated stainless steel did not contain carbides in its microstructure and it was quite soft. Consequently, during grinding and polishing a lot of asperities formed on surface (and particles embedded) which was especially pronounced on austenite grain boundaries. Therefore, it is postulated that coating growth defects preferably form as a consequence of difficulties in surface preparation.

- It was found that, nanolayered TiAlN/TiSiN coating generally grows with larger columnar grains on tool-steels with tempered martenzite microstructure, and on WC/Co, than on surgical stainless steel with austenite containing.

- Lower surface roughness (Sa) was detected on coating deposited with higher degree of rotation (2-fold, 3-fold). Considering that surface roughness is also affected by coating thickness, decrease in surface roughness is attributed to combined effects of rotation during deposition and increase in coating thickness.

- Coating deposited with 1-fold rotation displayed pronounced grain agglomeration, uneven surface topography, and higher roughness on a nano level. This is a result of high deposition rate and low ion bombardment.

- Smaller columnar grains were detected on coating deposited with 1-fold rotation, than 2-fold and 3 -fold. However, no clear dependence of coatings columnar grain size on degrees of rotation during deposition was observed.

- In order to better understand influence of rotation on topography and on coating grain size, additional comprehensive investigation is required.

Author Contributions: Conceptualization, A.M. and P.T.; methodology, A.M., P.T., L.K. and P.P.; validation, D.K. and A.M.; investigation, V.T., P.T., and L.K.; resources, B.S. and P.P.; writing - original draft preparation, V.T. and P.T.; writing - review and editing A.M., L.K., and B.S.; visualization, A.M. and D.K.; supervision, B.S. and P.P.; project administration A.M. and P.P.; funding acquisition, A.M., B.S. and P.P.

Funding: This research was funded by Serbian-Slovenian bilateral project (2018-2019) grant 48. This work was also funded by the Slovenian Research Agency (program P2-0082) and European Regional Development Funds (CENN Nanocenter, OP13.1.1.2.02.006).

Acknowledgments: Special thanks to Miha Čekada, Institute "Jožef Stefan" (Ljubljana, Slovenia) for all the help and for providing the resources needed for the investigation.

Conflicts of Interest: The authors declare no conflict of interest. 


\section{References}

1. Panjan, P.; Drnovšek, A.; Kovač, J. Tribological aspects related to the morphology of PVD hard coatings. Surf. Coat. Technol. 2017, doi:10.1016/j.surfcoat.2017.09.084.

2. Zhang, T.F.; Ding, J.C.; Kim, C.M.; Park, S.W.; Yang, Y.; Kim, K.H.; Kwon, S.H. Enhanced Corrosion Resistance of PVD-CrN Coatings by ALD Sealing Layers. Nanoscale Res. Lett. 2017, 12, 1-8, doi:10.1186/s11671-017-2020-1.

3. Luo, Q.; Lewis, D.B.; Hovsepian, P.E.; Münz, W.-D. Transmission Electron Microscopy and X-ray Diffraction Investigation of the Microstructure of Nanoscale Multilayer TiAlN/VN Grown by Unbalanced Magnetron Deposition. J. Mater. Res. 2011, 19, 1093-1104, doi:10.1557/JMR.2004.0143.

4. Panjan, P.; Gselman, P.; Kek-Merl, D.; Čekada, M.; Panjan, M.; Dražić, G.; Bončina, T.; Zupanič, F. Growth defect density in PVD hard coatings prepared by different deposition techniques. Surf. Coat. Technol. 2013, 237, 349-356, doi:10.1016/j.surfcoat.2013.09.020.

5. Sakurai, M.; Toihara, T.; Wang, M.; Kurosaka, W.; Miyake, S. Surface morphology and mechanical properties of nanoscale TiAIN/SiNx multilayer coating deposited by reactive magnetron sputtering. Surf. Coat. Technol. 2008, 203, 171-179, doi:10.1016/j.surfcoat.2008.08.060.

6. Lin, J.; Moore, J.J.; Sproul, W.D.; Mishra, B.; Wu, Z.; Wang, J. The structure and properties of chromium nitride coatings deposited using $\mathrm{dc}$, pulsed dc and modulated pulse power magnetron sputtering. Surf. Coat. Technol. 2010, 204, 2230-2239, doi:10.1016/j.surfcoat.2009.12.013.

7. Shah, H.N.; Jayaganthan, R.; Kaur, D. Influence of silicon content on the microstructure and hardness of CrN coatings deposited by reactive magnetron sputtering. Mater. Chem. Phys. 2010, 121, 567-571, doi:10.1016/j.matchemphys.2010.02.024.

8. Petrov, I.; Barna, P.B.; Hultman, L.; Greene, J.E. Microstructural evolution during film growth. J. Vac. Sci. Technol. A Vac. Surf. Film. 2003, 21, S117-S128, doi:10.1116/1.1601610.

9. Kakaš, D.; Škorić, B.; Terek, P.; Kovačević, L.; Vilotić, M. Mechanical properties of tin coatings deposited at different temperatures by IBAD process. FME Trans. 2012, 40, 37-42.

10. Suchea, M.; Christoulakis, S.; Tibeica, C.; Katharakis, M.; Kornilios, N.; Efthimiopoulos, T.; Koudoumas, E. Structural and morphological properties of thin $\mathrm{ZnO}$ films grown by pulsed laser deposition. Appl. Surf. Sci. 2008, 254, 5475-5480, doi:10.1016/j.apsusc.2008.02.112.

11. Fu, T.; Shen, Y.G.; Zhou, Z.F.; Li, K.Y. Surface morphology of sputter deposited W-Si-N composite coatings characterized by atomic force microscopy. Mater. Sci. Eng. B Solid-State Mater. Adv. Technol. 2005, 123, 158162, doi:10.1016/j.mseb.2005.07.017.

12. Wang, M.; Toihara, T.; Sakurai, M.; Kurosaka, W.; Miyake, S. Surface morphology and tribological properties of DC sputtered nanoscale multilayered TiAlN/CNx coatings. Tribol. Int. 2014, 73, 36-46, doi:10.1016/j.triboint.2014.01.008.

13. Anders, A. A structure zone diagram including plasma-based deposition and ion etching. Thin Solid Film. 2010, 518, 4087-4090, doi:10.1016/j.tsf.2009.10.145.

14. Miletić, A.; Panjan, P.; Škorić, B.; Čekada, M.; Dražič, G.; Kovač, J. Microstructure and mechanical properties of nanostructured Ti-Al-Si-N coatings deposited by magnetron sputtering. Surf. Coat. Technol. 2014, 241, 105-111, doi:10.1016/j.surfcoat.2013.10.050.

15. Oliver, W.C.; Pharr, G.M. An improved technique for determining hardness and elastic modulus using load and displacement sensing indentation experiments. J. Mater. Res. 1992, 7, 1564-1583, doi:10.1177/10.1557/JMR.1992.1564.

16. Panjan, P.; Čekada, M.; Panjan, M.; Kek-Merl, D.; Zupanič, F.; Čurković, L.; Paskvale, S. Surface density of growth defects in different PVD hard coatings prepared by sputtering. Vacuum 2012, 86, 794-798, doi:10.1016/j.vacuum.2011.07.013.

17. Lyman, T. Metals Handbook - 8th Edition: Vol. 7: Atlas of Microstructures of Industrial Alloys; 8th ed.; American Society for Metals, 1972.

18. Davis, J.R. Asm Specialty Handbook: Stainless Steels; 1994; Vol. 37; ISBN 0871706490. 
19. Gselman, P. PVD-defects and their influence on physicochemical properties of coating/substrate system, University of Maribor, Maribor, 2014.

20. Panjan, M. Influence of substrate rotation and target arrangement on the periodicity and uniformity of layered coatings. Surf. Coat. Technol. 2013, 235, 32-44, doi:10.1016/j.surfcoat.2013.06.126.

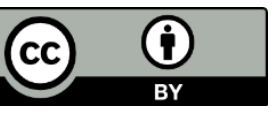

(C) 2020 by the authors. Submitted for possible open access publication under the terms and conditions of the Creative Commons Attribution (CC BY) license (http://creativecommons.org/licenses/by/4.0/). 